\title{
Hippocampal Abnormalities and Enhanced Excitability in a Murine Model of Human Lissencephaly
}

\author{
Mark W. Fleck, ${ }^{1}$ Shinji Hirotsune, ${ }^{2}$ Michael J. Gambello, ${ }^{2}$ Emily Phillips-Tansey, ${ }^{1}$ Gregory Suares, ${ }^{1}$ \\ Ronald F. Mervis, ${ }^{3}$ Anthony Wynshaw-Boris, ${ }^{2}$ and Chris J. McBain ${ }^{1}$ \\ ${ }^{1}$ Laboratory of Cellular and Molecular Neurophysiology, National Institute of Child Health and Human Development, \\ National Institutes of Health, Bethesda, Maryland 20892, ${ }^{2}$ Genetic Disease Research Branch, National Human Genome \\ Research Institute, National Institutes of Health, Bethesda, Maryland 20892, and ${ }^{3}$ Neuro-Cognitive Research Labs, \\ Columbus, Ohio 43212
}

Human cortical heterotopia and neuronal migration disorders result in epilepsy; however, the precise mechanisms remain elusive. Here we demonstrate severe neuronal dysplasia and heterotopia throughout the granule cell and pyramidal cell layers of mice containing a heterozygous deletion of Lis 1 , a mouse model of human 17p13.3-linked lissencephaly. Birth-dating analysis using bromodeoxyuridine revealed that neurons in Lis 1+/- murine hippocampus are born at the appropriate time but fail in migration to form a defined cell layer. Heterotopic pyramidal neurons in Lis 1+/- mice were stunted and possessed fewer dendritic branches, whereas dentate granule cells were hypertrophic and formed spiny basilar dendrites from which the principal axon emerged. Both somatostatin- and parvalbumin-containing inhibitory neurons were heterotopic and displaced into both stratum radiatum and stratum lacunosum-moleculare. Mechanisms of synaptic transmission were severely disrupted, revealing hyperexcitability at Schaffer collateral-CA1 synapses and depression of mossy fiber-CA3 transmission. In addition, the dynamic range of frequencydependent facilitation of Lis 1+/- mossy fiber transmission was less than that of wild type. Consequently, Lis1+/- hippocampi are prone to interictal electrographic seizure activity in an elevated $\left[\mathrm{K}^{+}\right]_{0}$ model of epilepsy. In Lis $1+/-$ hippocampus, intense interictal bursting was observed on elevation of extracellular potassium to $6.5 \mathrm{~mm}$, a condition that resulted in only minimal bursting in wild type. These anatomical and physiological hippocampal defects may provide a neuronal basis for seizures associated with lissencephaly.

Key words: lissencephaly; platelet-activating factor acetylhydrolase; knockout mouse; hippocampus; bromodeoxyuridine; Golgi; epilepsy; potassium
A number of genetic mutations that disrupt normal development of the human cerebral cortex have been described (for review, see Walsh, 1999). Classical or Type I lissencephaly defines a subgroup of human neuronal migration disorders characterized by generalized agyria/pachygyria, four abnormal cortical layers, enlarged ventricles, generalized neuronal heterotopias, and corpus callosum defects (Barkovich et al., 1991; Dobyns and Truwit 1995). In the United States, 1 in 40,000 infants is born annually with Type I lissencephaly, including isolated lissencephaly sequence (ILS) and Miller-Dieker syndrome (MDS). These infants present with severe cognitive and motor impairments and often die from seizures early in life. The defective gene, PAFAH1B1 also known as LIS1, was identified from patient samples with

\footnotetext{
Received Sept. 1, 1999; revised Jan. 10, 2000; accepted Jan. 12, 2000.

We thank Dr. Katalin Toth for her help throughout this study, Timothy Pindell and Jody McKean for their contribution to the Golgi staining, dendritic analysis, and spine counting, and Drs. Vittorio Gallo and Mark L. Mayer for critically reading this manuscript.

Correspondence should be addressed to Dr. Chris J. McBain, Laboratory of Cellular and Molecular Neurophysiology, National Institute of Child Health and Human Development, Building 49/5A72, 49 Convent Drive, National Institutes of Health, Bethesda, MD 20892-4495. E-mail: chrismcb@codon.nih.gov.

Dr. Fleck's current address: Department of Pharmacology and Neuroscience, Albany Medical College, A-136 47 New Scotland Avenue, Albany, NY 12208.

Dr. Hirotsune's current address: The Institute for Animal Genetics, Odakura, Nishigo, Nishi-Shirakawa Fukushima 961, Japan.

Dr. Gambello's and Dr. Wynshaw-Boris's current address: Departments of Pediatrics and Medicine, School of Medicine, University of California San Diego, La Jolla, CA 92093.

Copyright (C) 2000 Society for Neuroscience $0270-6474 / 00 / 202439-12 \$ 15.00 / 0$
}

informative deletions of 17p13.3 (Reiner et al., 1993) and confirmed when dominant point mutations and a hemizygous intragenic deletion of the LIS1 gene were found in ILS patients (Lo Nigro et al., 1997). The LIS1 gene (Reiner et al., 1993) encodes a brain-specific, $45 \mathrm{kDa}$ noncatalytic subunit of platelet-activating factor acetylhydrolase-1b (PAFAH1b) (Hattori et al., 1994), an enzyme that inactivates PAF.

Seizures are universal in humans with Type I lissencephaly (Dobyns et al., 1993). Precisely how a deficiency of LIS1 protein disrupts normal brain development and precipitates seizures is unknown. The anatomical defects seen in Type I lissencephaly and the developmental pattern of LIS1 protein expression are consistent with an important role in neuronal migration (Reiner et al., 1995; Albrecht et al., 1996). The demonstration that PAF collapses neuronal growth cones (Clark et al., 1995) and reduces neuronal migration in vitro (Bix and Clark 1998) suggests that PAF may play a role in CNS development. PAFAH1b has strong evolutionary conservation, and in nonmammalian organisms (e.g., Aspergillus nidulans) its ortholog, nudF, is required for nucleus translocation along elongated processes (Morris et al., 1998a). In the mammalian brain, PAFAH1b1 interacts with elements of the microtubule network (Morris et al., 1998b; Sapir et al., 1997), strengthening the connection between LIS1 protein and neuronal migration. Experimental support for abnormal neuronal migration in lissencephaly has come from mice with a hemizygous deletion of the Lis1 gene. Lis 1+/- mice possess similar developmental brain abnormalities observed in ILS and 
MDS as well as reduced cell migration both in vivo and in vitro, and they display lethal tonic-clonic seizures (Hirotsune et al., 1998).

Although the anatomical disruptions of the cerebral cortex in ILS and MDS are profound and have been well studied, much less is known about the hippocampus. Dilatation of the posterior horns of the lateral ventricles is common in Type I lissencephaly (Pilz and Quarrell, 1996) suggesting incomplete development of adjacent structures, including the hippocampus. However, no detailed anatomical data exist on the hippocampus in Type I lissencephaly. In addition, the functional consequences of abnormal or incomplete migration that might account for cognitive impairments or seizure generation have not been examined at the cellular or synaptic level. This report describes the hippocampal disorganization in a mouse model of human Type I lissencephaly and may provide a basis for epilepsy related to neuronal migration defects.

\section{MATERIALS AND METHODS}

\section{Lis1 mutant mice}

The mutant Lis1 allele designated Lis $1^{\text {ex6neo-8 }}$ (or Lis1-neo) was generated by gene targeting, as previously described (Hirotsune et al., 1998). All animal experiments were performed under protocols approved by the National Human Genome Research Institute and National Institute of Child Health and Human Development Animal Care and Use Committees and followed the National Institutes of Health Guidelines Using Animals in Intramural Research.

\section{Histology, immunohistochemistry, Golgi analysis, and bromodeoxyuridine birth dating}

Immunohistochemistry. Adult mice were deeply anesthetized with isofluorane (Ohmeda, Liberty Corner, NJ) and transcardially fixed with $0.9 \%$ $\mathrm{NaCl}$ and $4 \%$ paraformaldehyde. Hippocampal sections $(50 \mu \mathrm{m})$ were prepared on a freezing microtome. Slices were incubated for $3 \mathrm{hr}$ at room temperature with anti-calretinin (1:500, Chemicon, Temecula, CA), antihuman somatostatin (1:100, Dako, Glostrup, Denmark), or monoclonal anti-parvalbumin (PV) (1:1000, Sigma, St. Louis, MO). Polyclonal anticalbindin (CB) D-28K (1:400, Chemicon) was incubated at $4^{\circ} \mathrm{C}$ for $48 \mathrm{hr}$. For calretinin and calbindin immunohistochemistry, sections were incubated overnight at $4^{\circ} \mathrm{C}$ with biotinylated goat anti-rabbit IgG (1:200, Vector Laboratories, Burlingame, CA); for parvalbumin immunohistochemistry, biotinylated goat anti-mouse $\operatorname{IgG}$ (1:200, Sigma) was used. For somatostatin, unconjugated goat anti-rabbit $\operatorname{IgG}\left(1: 200\right.$, Vector) at $4^{\circ} \mathrm{C}$ was used followed by a $1 \mathrm{hr}$ incubation with rabbit peroxidase antiperoxidase (1:100, Sigma). All proteins were visualized using diaminobenzidine. Immunostained sections were then Nissl-counterstained (see below) to reveal the location of the heterotopic cells of interest in relation to the multiple pyramidal cell layers.

Histology. For Nissl staining, $1 \%$ cresyl violet acetate was applied to sections for $1 \mathrm{~min}$, rinsed with $\mathrm{dH}_{2} \mathrm{O}$, followed by differentiation in $70 \%$ ethanol $/ 2 \%$ glacial acetic acid. Stained sections were dehydrated in ethanol and coverslipped.

Golgi analysis. Blocks of coronally cut $10 \%$ formalin-fixed mouse brain encompassing the hippocampus were stained with the rapid Golgi method as detailed elsewhere (Valverde, 1976). For the Golgi study, seven wild-type controls and four Lis $1+/-$ mice were used. Briefly, the blocks were impregnated using osmium tetroxide plus potassium dichromate followed by immersion in silver nitrate. After dehydration, the blocks were embedded in nitrocellulose, and coronal sections were cut at $120 \mu \mathrm{m}$. For dendritic analysis of CA1 pyramidal neurons, camera lucida drawings of the basilar tree were prepared. The extent and distribution of dendritic branching of the CA1 neurons was evaluated by Sholl analysis. Statistical significance was evaluated using a repeated measures ANOVA with a Bonferroni post hoc test. The total dendritic length for the basilar tree of each CA1 neuron was calculated by tracing camera lucida drawings with a planimeter. Statistical analysis was performed by ANOVA followed by the Tukey post hoc test.

Bromodeoxyuridine birth dating. Pregnant dams were injected at embryonic day (E) $11,13,14,15$, and 17, and pups were killed at postnatal day (P) 30. Hippocampi were sectioned $(50 \mu \mathrm{m})$. DNA was denatured by a $60 \mathrm{~min}$ incubation in $2 \mathrm{~N} \mathrm{HCl}$. Slices were blocked for $60 \mathrm{~min}$ using unconjugated anti-mouse $\operatorname{IgG}(1: 10$, Sigma), then incubated with antibromodeoxyuridine (BrdU) IgG (1:20-1:100, Becton Dickinson). Biotinylated goat anti-mouse (1:100, Sigma) was used as a secondary antibody. BrdU expression was visualized using ABC (Vector) and diaminobenzidine.

\section{Hippocampal electrophysiology}

Transverse hippocampal slices $(350-400 \mu \mathrm{m})$ were obtained from P28-60 mice as described previously (Maccaferri and McBain, 1995). Mice were anesthetized by volatile inhalation of isofluorane and decapitated. Hippocampal slices were prepared in standard ice-cold artificial CSF (ACSF) (see below) containing $0.5 \mathrm{~mm} \mathrm{CaCl}_{2}$ and $10 \mathrm{~mm} \mathrm{MgSO}_{4}$. For recording, slices were bathed in ACSF containing (in $\mathrm{mM}$ ): 130 $\mathrm{NaCl}, 24 \mathrm{NaHCO}_{3}, 3.5 \mathrm{KCl}, 1.25 \mathrm{NaH}_{2} \mathrm{PO}_{4}, 2.5 \mathrm{CaCl}_{2}, 1.25 \mathrm{MgSO}_{4}, 10$ glucose, $95 \% \mathrm{O}_{2} / 5 \% \mathrm{CO}_{2}$, $\mathrm{pH}$ 7.3. For current-clamp recordings, electrodes contained (in mM): $130 \mathrm{~K}$-gluconate, $10 \mathrm{NaCl}, 10 \mathrm{HEPES}, 0.2$ EGTA, $1 \mathrm{MgCl}_{2}, \mathrm{pH} 7.2$, and $0.5 \%$ biocytin. For voltage-clamp experiments, electrodes contained (in mM): $80 \mathrm{CsCl}, 50 \mathrm{CsF}, 10 \mathrm{HEPES}, 10$ EGTA, 1 QX-314, $1 \mathrm{MgCl}_{2}, 0.5 \mathrm{CaCl}_{2}$, and $0.5 \%$ biocytin.

Extracellular recordings were made using low-resistance patch pipettes filled with gassed extracellular solution. Stimulating electrodes (Frederick Haer and Co., Bowdoinham, ME, stainless steel) were positioned in the appropriate cell layer using infrared-DIC optics, and brief constant current pulses $(50-100 \mu \mathrm{sec})$ were used to evoke field EPSPs (fEPSPs). Mossy fiber synaptic events were distinguished from associational/commissural inputs to CA3 by the use of Group 2 metabotropic glutamate receptor agonists (mGluRs): $\left(2 S, 2^{\prime} R, 3^{\prime} R\right)-2-\left(2^{\prime}, 3^{\prime}\right.$-dicarboxycyclopropyl)glycine (DCG-IV) $100 \mathrm{~nm}$ or $(1 S, 3 R)$-1-aminocyclopentane-1,3dicarboxylic acid (ACPD) $1 \mu \mathrm{M}$. In all experiments involving mossy fiber transmission, the DCG-IV (or ACPD)-sensitive record was subtracted out of the total trace to allow analysis of mossy fiber synaptic activity in isolation.

In the "High $\left[\mathrm{K}^{+}\right]_{\mathrm{o}}$ " model of epilepsy, $\left[\mathrm{K}^{+}\right]_{\mathrm{o}}$ was sequentially elevated from 3.5 to $6.5,8.5$, and 10.5 mM. Extracellular recordings of spontaneous and evoked interictal bursts were acquired using Clampfit or Axoscope (Axon Instruments). Burst intensity was estimated as described previously (Korn et al., 1987). Briefly, the entire length of the burst waveform was measured, and an identical burst-free segment was subtracted. The resulting digital value termed the "coastline bursting index" (CBI) is correlated with the intensity of the underlying activity and expressed in arbitrary units. Twenty spontaneous events per condition were analyzed, and the results were averaged.

\section{RESULTS}

\section{Hippocampal histopathology}

We have shown previously that mice with a hemizygous deletion of the Lis 1 gene possess developmental brain abnormalities associated with the cortex, olfactory bulb, and hippocampus (Hirotsune et al., 1998). In the present study we now focus on the hippocampal formation to determine the nature and extent of these structural abnormalities and how they impact hippocampal synaptic function, and we use a combination of anatomical and electrophysiological techniques.

The principal cell layers (i.e., CA subfields and granule cell layer) of the Lis1+/- mouse hippocampus are severely disorganized. Figure 1 illustrates cresyl violet-stained sections of adult wild-type and Lis $1+/-$ hippocampus. Pyramidal cell somata in both CA1 and CA3 are heterotopic and loosely packed, and they often formed multiple distinct cell layers with many cells displaced throughout stratum oriens to the alvear surface (Fig. 1). These heterotopic bands appear to radiate throughout the entire subfield and are interspersed with single cells (presumably inhibitory interneurons) between adjacent bands of principal cells. Disruption of the dentate gyrus granule cell layer was less severe. Although granule cells usually were not heterotopic, they were "loosely" packed into a cell layer, but clusters of granule cells were often observed deep within the hilar layer, blurring the granule cell-hilar border. In Figure 1B3, only the upper blade of the granule cell layer was dispersed, whereas the lower blade was 

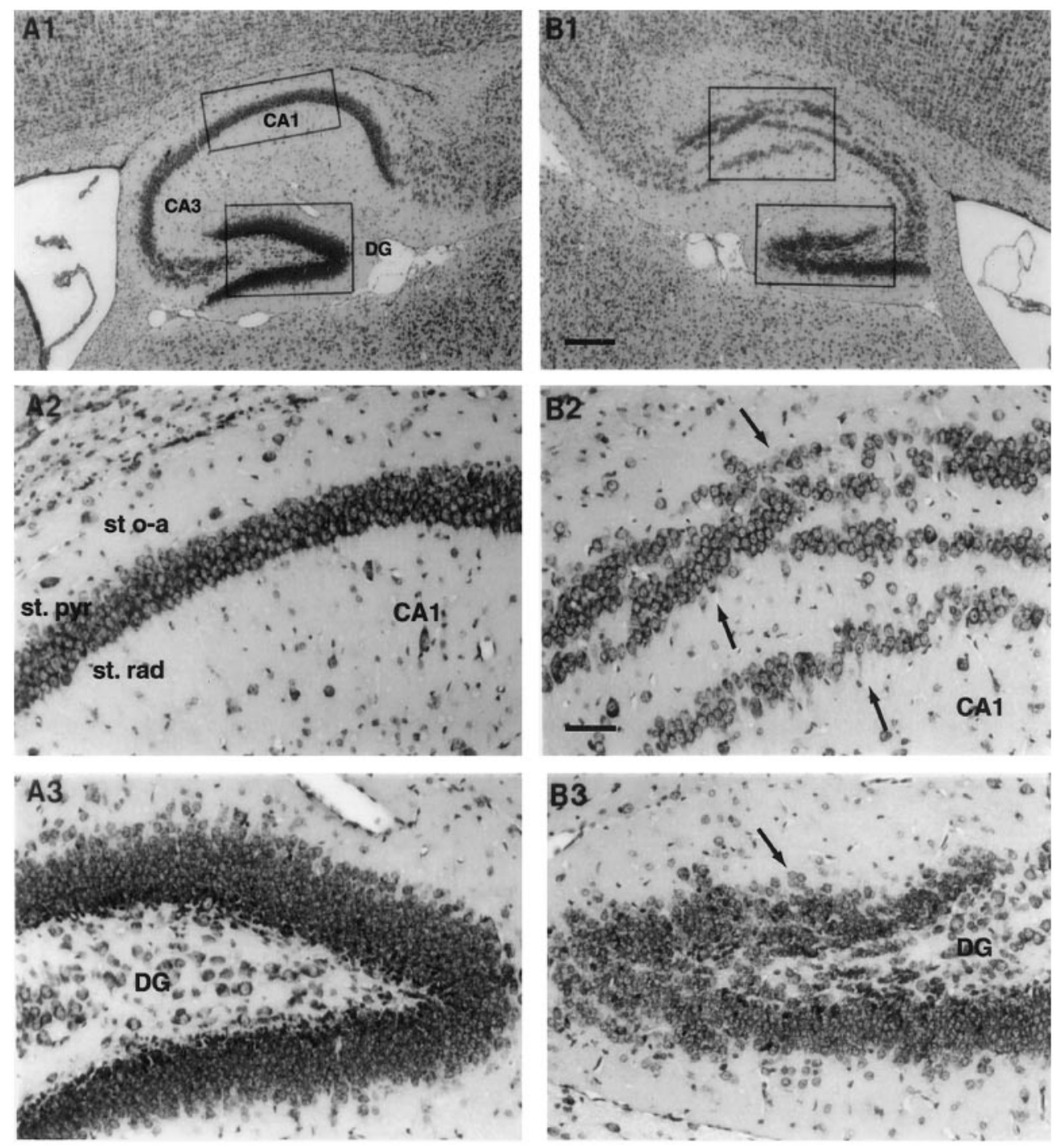

Figure 1. Heterotopia of the Lis1+/hippocampus. Nissl-stained sections of adult Lis 1+/ - mouse hippocampus reveal the cellular disorganization and heterotopia of the principal cell layers. $A 1$, The normal wild-type hippocampus $(5 \times)$ is characterized by tightly packed CA1 and CA3 pyramidal $(A 2,25 \times)$ and granule cell layers $(D G)(A 3,25 \times)$, typically only a few cells thick. In contrast, severe pyramidal neuron heterotopia exists in the Lis 1+/- hippocampus (B1$B 3,5 \times)$. In CA1, the pyramidal cell layer is loosely packed, with cells forming distinct, multiple layers that radiate from the stratum oriens/alveus into the stratum radiatum $(B 2,25 \times)$. In the dentate gyrus, the granule cell layer is similarly disorganized into a diffuse band. The upper blade of the dentate gyrus granule cells is more diffusely packed than the lower blade. The loose organization of the granule cell layer obscures the hilar-dentate gyrus border (B3, $25 \times)$. st o- $a$, Stratum oriens-alveus; st. rad, stratum radiatum; st. pyr, stratum pyramidale. Scale bars: $A 1, B 1,250 \mu \mathrm{m}$; $A 2, A 3, B 2, B 3,66 \mu \mathrm{m}$. more "normal." In general, either blade of the granule cell layer could show disruption, and the abnormalities associated with Lis1 deficiency were not restricted to the upper or lower blade of the dentate gyrus. The hippocampi of several hundred Lis $1+/-$ mice have now been analyzed, and although the severity of the heterotopia was quite variable, the pattern of disruption and heterotopia described above is stereotypical of these animals.

\section{BrdU birth dating reveals a normal pattern of neurogenesis but incomplete neuronal migration}

Developmental processes within the hippocampus follow patterns similar to development of the neocortex, with the exception of the long-lasting neurogenesis of the dentate gyrus granule cells and their "outside-in" gradient of positioning (Cowan et al., 1980). Hippocampal principal cells migrate along the radial glia and are positioned in the hippocampal plate following an "inside-out" gradient. By E14-15 principal neurons are sandwiched between populations of GABAergic neurons in the subplate and the inner marginal zone, which are destined to become the stratum oriens and stratum radiatum, respectively (Soriano et al., 1994). Thus each plexiform layer of the developing hippocampus is populated by a characteristic neuronal population, the distribution of which does not overlap.

By using bromodeoxyuridine (BrdU) labeling, we determined whether cellular malformation of the Lis1+/- hippocampus resulted from abnormal neurogenesis at a particular developmental time point. Pregnant dams were injected with BrdU on E11, 13, 14,15 , and 17 to label actively dividing cells, and the distribution of BrdU-positive cells was examined at P14-30 in Lis 1+/- mice and wild-type littermates (Fig. 2). At E11 only a small number of BrdU cells were observed. At this time point, however, a significantly higher number of BrdU-positive cells were observed in Lis 1+/- CA1 stratum pyramidale than were wild type, perhaps indicating early neurogenesis in these animals (Table 1). Most cells in the CA1-CA3 subfields are born between E13 and E14 in both the wild-type and the Lis1+/- mouse. The distribution of E13 BrdU-labeled cells was similar in both wild-type and Lis1+/- animals; cells were observed throughout all subfields. Furthermore, similar numbers of BrdU-positive cells were generated in both wild type and Lis1+/- (Table 1). E14 BrdU-labeled neurons were most numerous in the tightly packed stratum pyramidale in wild type; however, most BrdU-positive cells in the Lis 1+/- hippocampus were observed throughout the entire CA subfield from the stratum oriens-alveus to the stratum lacunosummoleculare. We were particularly struck by the observation that BrdU-labeled cells were observed throughout all of the heterotopic bands of pyramidal cells in the CA1 subfield and were not 
Figure 2. BrdU birth dating reveals appropriate neurogenesis. BrdU birth dating was used to determine whether neurons are born at the appropriate point in development in the Lis 1+/- hippocampus. In tissue sections (P30) from animals injected with BrdU at embryonic day 11 (E11), BrdU labeled relatively few cells located primarily at the hippocampal fissure, the hilus, the molecular layer, and the subiculum in wild-type animals. A similar pattern of BrdU labeling was observed in the Lis1+/hippocampus. By E13, BrdU-labeled neurons were distributed widely throughout all hippocampal subfields. In wild type, BrdU-labeled neurons were primarily observed in both the dentate gyrus-hilus, and in stratum pyramidale, stratum oriens, stratum radiatum, and subiculum. In Lis1+/- hippocampus, BrdU-labeled cells were widely distributed throughout all subfields from the stratum oriens-stratum radiatum. High numbers of BrdU-labeled cells were also observed in the granule cell layer and hilus. In E14 injected animals, most wild-type BrdU-labeled cells were observed in a tight, well defined band analogous to the principal cell layers of the dentate gyrus and pyramidal cell layer. In the Lis $1+/-$ animal, although similar numbers of neurons were BrdU-labeled (Table 1), neurons had failed to fully complete migration and were diff usely scattered throughout the CA1 subfield and the dentate gyrus. In addition, large numbers of BrdU-labeled cells were observed in the fimbria-fornix areas. By E17, BrdU labeling declined in the CA subfields and was highest within the dentate gyrus cell layer of both wild-type and Lis 1+/- hippocampus. st. or, Stratum oriens-alveus; st. rad, stratum radiatum; st. pyr, stratum pyramidale; sub, subiculum; $h f$, hippocampal fissure.


Table 1. Developmental expression pattern of BrdU-positive cells in wild-type and Lis $1+/-$ mice

\begin{tabular}{|c|c|c|c|c|c|c|c|c|c|}
\hline $\begin{array}{l}\mathrm{E} 11+/+ \\
(n=5)\end{array}$ & $\begin{array}{l}\mathrm{E} 11+/- \\
(n=7)\end{array}$ & $\begin{array}{l}\mathrm{E} 13+/+ \\
(n=7)\end{array}$ & $\begin{array}{l}\mathrm{E} 13+/- \\
(n=7)\end{array}$ & $\begin{array}{l}\mathrm{E} 14+/+ \\
(n=5)\end{array}$ & $\begin{array}{l}\mathrm{E} 14+/- \\
(n=6)\end{array}$ & $\begin{array}{l}\mathrm{E} 15+/+ \\
(n=10)\end{array}$ & $\begin{array}{l}\mathrm{E} 15+/- \\
(n=10)\end{array}$ & $\begin{array}{l}\mathrm{E} 17+/+ \\
(n=10)\end{array}$ & $\begin{array}{l}\mathrm{E} 17+/- \\
(n=8)\end{array}$ \\
\hline
\end{tabular}

CA1

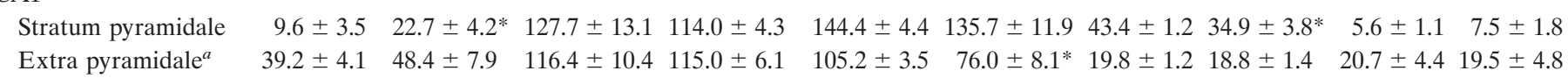
CA3

$\begin{array}{lllllrrrrrr}\text { Stratum pyramidale } & 12.6 \pm 3.8 & 14.4 \pm 2.4 & 70.3 \pm 5.8 & 58.0 \pm 4.3 & 117.2 \pm 5.8 & 123.4 \pm 7.9 & 38.4 \pm 2.2 & 29.3 \pm 2.3 * & 3.9 \pm 0.6 & 4.0 \pm 0.5 \\ \text { Extra pyramidale } & 16.8 \pm 2.7 & 25.4 \pm 3.0 & 80.3 \pm 6.4 & 73.0 \pm 11.4 & 70.2 \pm 7.5 & 60.0 \pm 3.9 & 12.8 \pm 1.1 & 18.4 \pm 1.3 & 6.1 \pm 1.1 & 8.9 \pm 1.4 \\ \text { Dentate gyrus } & 52.8 \pm 15.4 & 59.5 \pm 3.2 & 122.3 \pm 9.7 & 108.0 \pm 12.5 & 129.8 \pm 3.9 & 124.2 \pm 11.2 & 39.1 \pm 1.6 & 33.4 \pm 2.5 & 76.4 \pm 4.8 & 71.1 \pm 6.4\end{array}$

Pregnant dams were injected at E11, 13, 14, 15, and 17, and pups were killed at P30.

${ }^{a}$ Extra pyramidale is defined as the stratum radiatum, stratum oriens-alveus, and in the case of CA1 the stratum lacunosum-moleculare.

*Indicates statistical significance compared with age-matched wild-type at the $p<0.05$ level (Student's unpaired $t$ test).

restricted to a particular band at a particular developmental time point. This suggests that many of the cells within these discreet bands of stratum pyramidale are generated at a similar time point; however, these clusters of cells fail in migration to consol- idate into a single cell layer. A significantly lower number of E14 BrdU-labeled cells were observed in the extra pyramidal cell layers (i.e., stratum radiatum, oriens-alveus, and lacunosummoleculare). It is unclear whether this reflects a true reduction in 

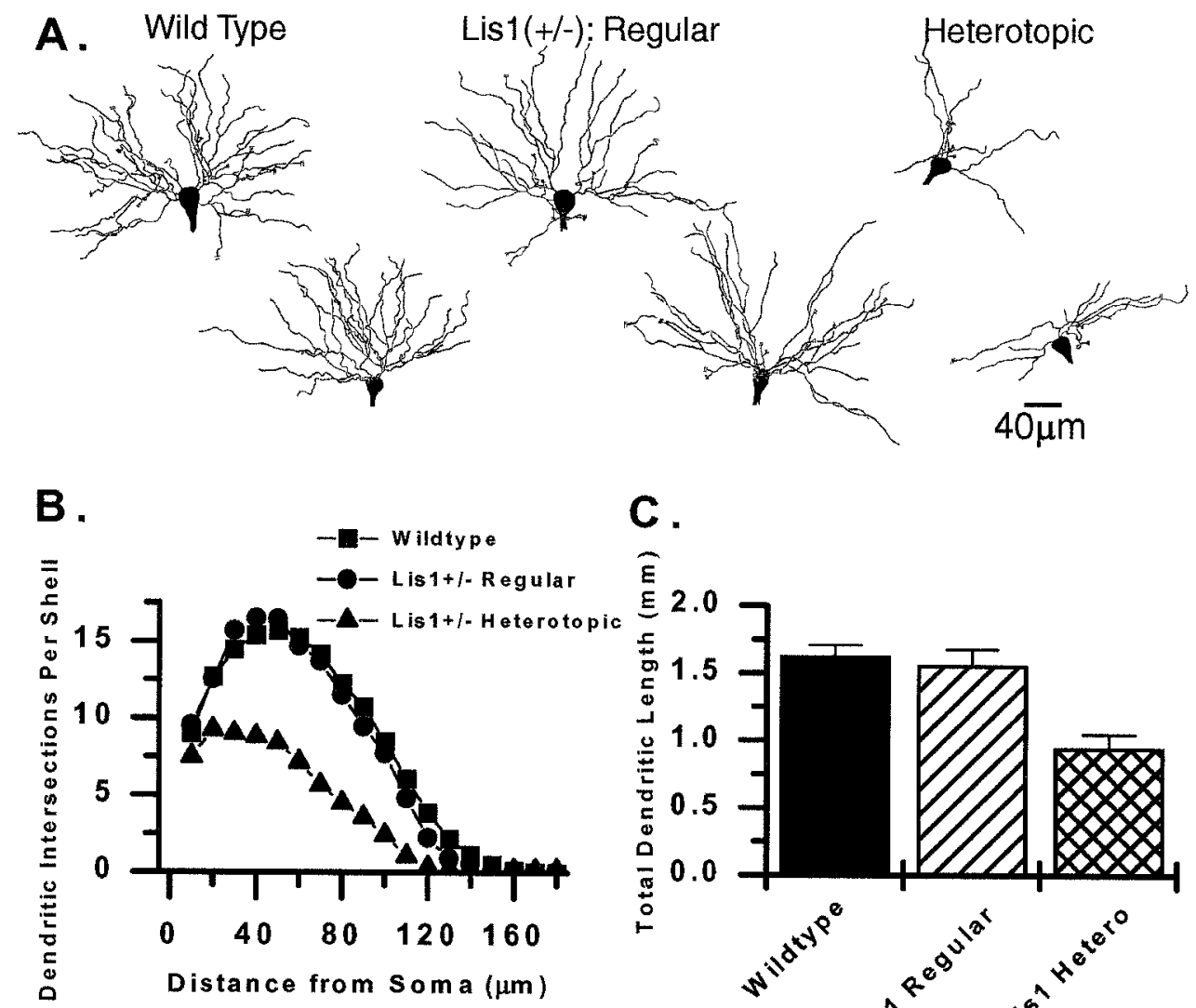

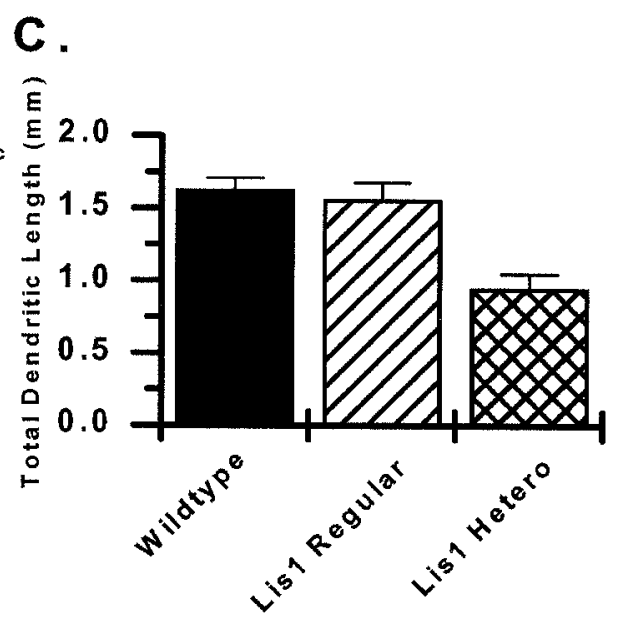

Figure 3. The basal dendrites of CA1 pyramidal neurons in the Lis1+/- hippocampus are stunted and possess few branches. $A$, Camera lucida drawings of six representative Golgi-stained CA1 pyramidal neuron basal dendrites from wildtype and Lis1+/- hippocampus. Two groups of CA1 pyramids were analyzed in the Lis1+/- hippocampus: those cells located in a cell layer most likely representing the stratum pyramidale (Regular) and those cells stranded in migration in the stratum oriens (Heterotopic). Note that heterotopic pyramidal neurons possess a significantly less elaborate dendritic arbor than both wild-type and regularly positioned Lis1+/- CA1 pyramids. B, Sholl analysis reveals that the basal dendrites of regular Lis $1+/-(n=20$ pyramids $)$ and wild-type $(n=35)$ CA1 pyramids are similar. In contrast, the dendrites of heterotopic Lis $1+/-$ neurons $(n=12)$ make significantly fewer intersections per shell and have a significantly reduced total dendritic length $(C)$. cell numbers or the difficulty in counting cells when multiple bands of interlaced principal cells are present throughout all CA1 subfields. By E15 and E17, BrdU labeling was markedly reduced in both CA1 and CA3 subfields but remained high in the granule cell layer of the dentate gyrus (Table 1). A significantly lower number of E15 BrdU-positive cells were observed in both Lis 1+/- CA1 and CA3 stratum pyramidale (Table 1).

Although cells in both wild-type and Lis $1+/-$ hippocampus are generated in nearly identical numbers (with few exceptions) at similar embryonic time points (Table 1), it is worthwhile noting that the scattered distribution of cells in the adult Lis $1+/-$ hippocampus does not allow us to determine whether heterotopic cells represent principal cell types or reflect an altered neurogenesis of inhibitory interneuron types. However, these data further demonstrate that the characteristic organization of the embryonic and early postnatal murine hippocampus is severely disrupted. This presumably results not from significant changes in the numbers of neurons being generated but an altered migration of both principal and inhibitory interneurons. Similar data were observed in three independent experiments.

\section{Golgi analysis of hippocampal neuron anatomy \\ CA1 pyramidal neurons}

We next examined pyramidal cell anatomy in brains of adult Lis 1 +/- mice and wild-type littermates after Golgi impregnation (Fig. 3). To evaluate anatomical differences, we compared the basilar dendritic arbor of CA1 pyramids in (1) control wild-type cells, (2) cells that had migrated to a location equivalent to stratum pyramidale, and (3) heterotopic pyramidal cells "stranded" in stratum oriens or stratum radiatum in the Lis $1+/-$ hippocampus. We chose to study the basilar dendritic tree because it was representative of morphological changes across the entire dendritic tree (i.e., both apical and basilar dendrites were similarly affected). The dendritic arbors of neurons from both wildtype and Lis $1+/-$ cells located within stratum pyramidale were not significantly different. In contrast, the dendritic arbor of heterotopic pyramidal cells was significantly smaller compared with both cell types (Fig. 3). Sholl analysis revealed that heterotopic pyramidal neurons made significantly fewer dendritic intersections per shell $(p<0.001)$ than pyramidal neurons. Similarly, the total dendritic length of heterotopic CA1 pyramidal cells was considerably reduced ( $949 \pm 99 \mu \mathrm{m}, p<0.001, n=12$ cell from four animals) compared with both control (1629 $\pm 79 \mu \mathrm{m}, n=20$ cells from four animals) and regular CA1 pyramidal neurons (1564 $\pm 114 \mu \mathrm{m}, n=35$, from seven animals). The total number of branch points was also significantly reduced ( $\sim 40 \%$ of control) in heterotopic pyramidal neurons compared with wild-type controls; mean number of branch points was 6.8 versus 16.8 per neuron, respectively. Of interest, the dendritic spine density was not different among the three groups; control wild type $=1.61 \pm$ 0.03 spines per micrometer $(n=35)$, Lis $1+/-$ stratum pyramidale neurons $=1.63 \pm 0.04(n=20)$, Lis $1+/-$ ectopic pyramidal cells $=1.45 \pm 0.09(n=12)$. These data reveal that neurons, within the presumed stratum pyramidale, are anatomically similar to wild type; however, heterotopic cells stranded within stratum oriens or stratum radiatum possess dendrites that are stunted and make fewer branches.

\section{Dentate gyrus granule cells}

Granule cells of adult mice lack basal dendrites (Seress and Mrzljak 1987; Spigelman et al., 1998), although they are transiently expressed during postnatal development. A recent study 
Figure 4. Hypertrophy of dentate gyrus granule cells and a decreased dynamic range of mossy fiber synaptic transmission in Lis $1+/-$. A, Representative camera lucida drawings of Golgi-impregnated dentate gyrus granule cells from wild type (left) and Lis $1+/-($ right $)$. Wild-type granule cells possess spiny apical dendrites, lack spines on their soma, and have an axon that emerges from the basal pole of the soma. In contrast, heterotopic Lis 1+/- granule cells located in the subgranular region have spiny basal dendrites (indicated by arrows) that give rise to the axon. Note that both the somata and basal dendrites are extremely spiny in both cases. The inset shows digital image of spiny soma and basal dendrites of the left Lis1+/- granule cell. Scale bars for main panels and inset: $15 \mu \mathrm{m} . B, C$, The dynamic range of frequency facilitation is reduced in Lis $1+/-$ mossy fiber-CA3 synapses. $B$, Amplitude of mossy fiber fEPSPs evoked at various stimulation frequencies before and after induction of LTP in wild type (left) and Lis $1+/-($ right $)$. Mossy fiber synapses were stimulated at a frequency of $0.0125 \mathrm{~Hz}$. Arrows indicate changes in the stimulation frequency $(0.025,0.05$, $0.1,0.2$, and $0.33 \mathrm{~Hz}$ ). Marked facilitation was observed at frequencies as low as $0.05 \mathrm{~Hz}$. After induction of LTP $(4 \times 100 \mathrm{~Hz}, 1 \mathrm{sec}, 0.03 \mathrm{~Hz})$, the stimulus intensity was decreased to avoid possible nonlinearities during frequency facilitation (Salin et al., 1996). Data are normalized to fEPSPs obtained at $0.025 \mathrm{~Hz}$. Right trace shows the identical experiment performed at mossy fiber synapses in Lis 1+/-; arrows are not shown in right trace for clarity. $C$, Summary graph from eight representative experiments in both wild type and Lis $1+/-$ shows the range of frequency facilitation before and after LTP induction normalized to $0.025 \mathrm{~Hz}$. The dynamic range of frequency facilitation is significantly less in Lis $1+/-$ animals before the induction of LTP $(p<$ 0.001 , two-tailed Student's $t$ test). After LTP the degree of facilitation is reduced both in wild type and in Lis $1+/-$ at frequencies above $0.05 \mathrm{~Hz}$. After LTP the degree of facilitation was similar in both Lis $1+/-$ and wild type ( $p=0.1$, two-tailed paired Student's $t$ test).
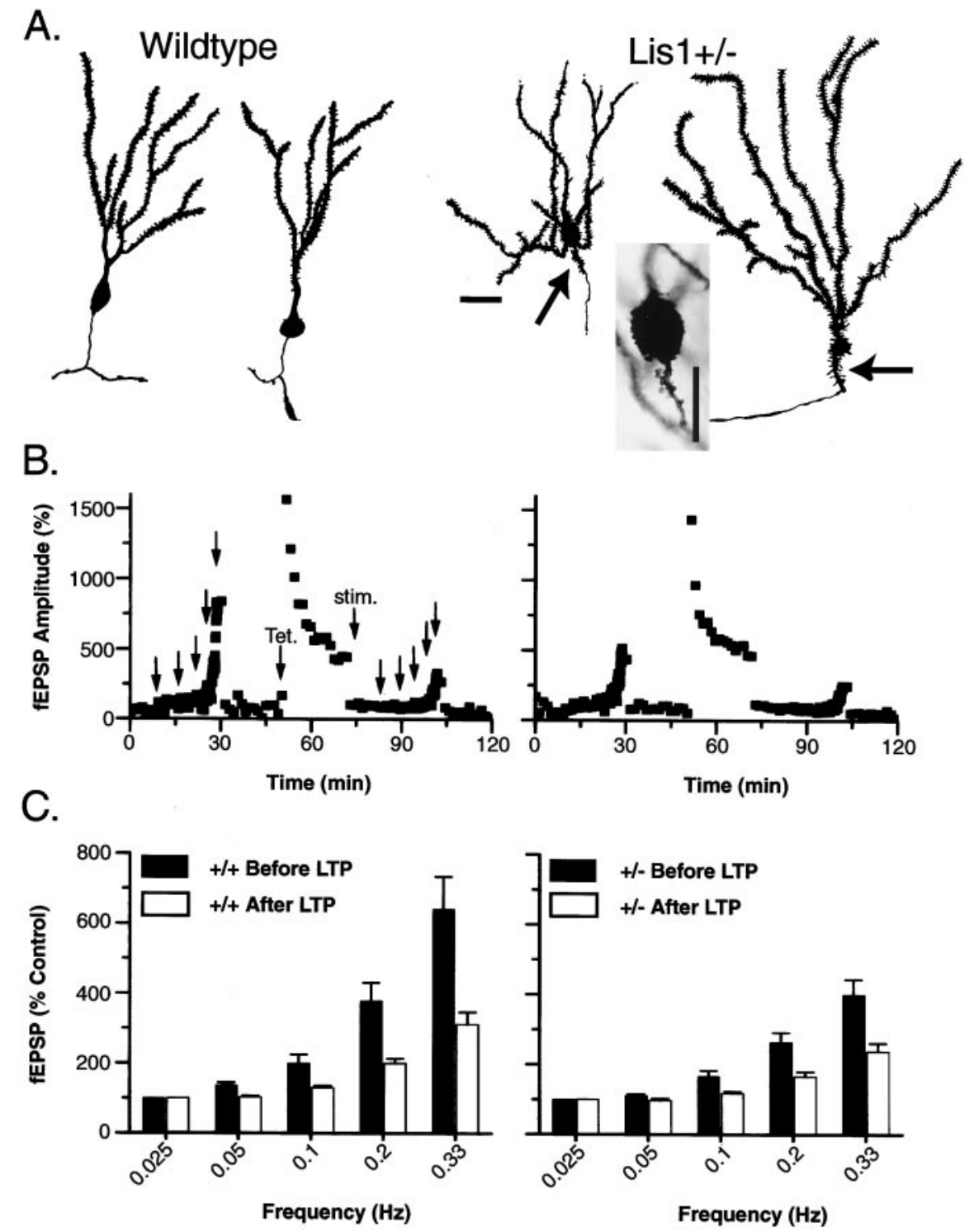

has demonstrated, however, that basal dendrites are a prominent feature of granule cells in rats with epilepsy induced by highfrequency stimulation of the perforant path, a model of temporal lobe epilepsy (Spigelman et al., 1998). Spiny basilar dendrites have also been described in dentate granule cells from adult epileptic human tissue (Franck et al., 1995). We next analyzed the anatomy of Golgi-stained dentate gyrus granule cells. Similar to pyramidal neurons, granule cells that migrated to a presumed cell layer were indistinguishable from wild-type granule cells. Striking abnormalities were observed, however, in heterotopic granule cells located in both the molecular layer and the subgranular region of the hilus (Fig. 4). Heterotopic Lis $1+/-$ dentate granule cells were hypertrophic and possessed a high incidence of spiny basilar dendrites from which emerged the mossy fiber axon. The diameters of granule cell somata were not different among the three cell groups (wild-type, normally positioned, and heterotopic granule cells); however, the somata of heterotopic granule cells were extremely spiny (Fig. 4). Further analysis of the presence of spiny basilar dendrites in wild-type and heterotopic Lis1+/granule cells demonstrated that $17 \%$ of wild-type granule cells (80 of 468 cells analyzed from 10 animals) possessed more than three spines (but fewer than eight) on their somata, but none possessed basal dendrites. In contrast, $83 \%$ of heterotopic Lis 1+/- granule cells (86 of 103 cells analyzed from four animals) possessed both spiny ( $>10$ spines) somata and basilar dendrites.

\section{Heterotopia of parvalbumin- and somatostatin-containing interneurons}

The profound cellular disorganization in both human lissencephaly and Lis $1+/-$ mouse clearly involves large numbers of pyramidal neurons. To determine whether local circuit inhibitory interneurons are similarly affected, we examined the distribution of immunohistochemically defined subpopulations of interneurons in the hippocampus of Lis $1+/-$ mice and littermate controls (Fig. 5).

In the wild-type hippocampus, the somata of PV-containing interneurons are predominantly located near or within the stratum pyramidale and stratum oriens (Fig. 5A1,A2). Their axons are restricted to stratum pyramidale where they form symmetrical synapses on the somata, proximal dendrites, and axon initial segments of pyramidal neurons (Freund and Buzsaki, 1996). In 

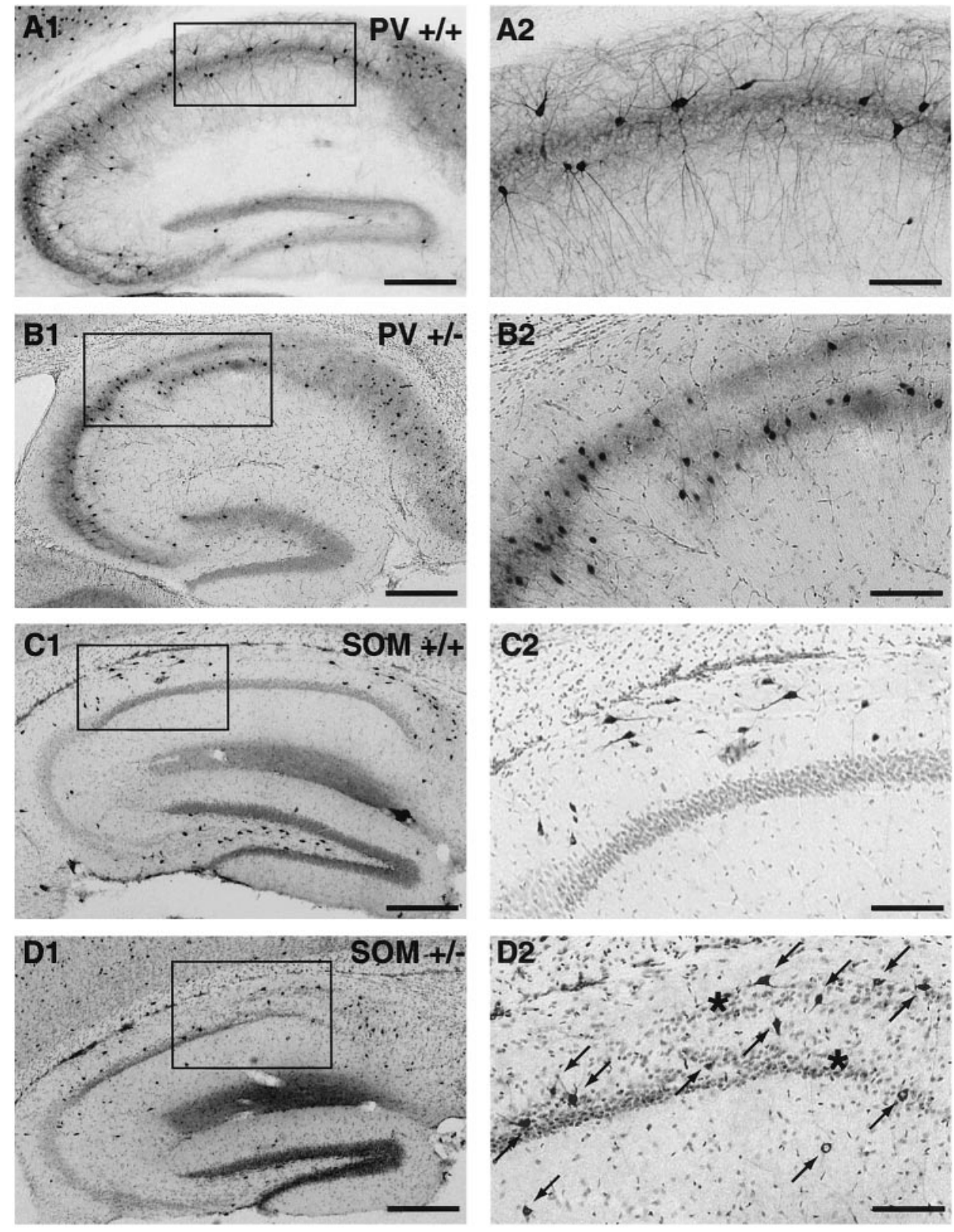
amids and deep within the stratum radiatum areas (the boxed region in D1 is shown at high magnification in D2). In this particular hippocampus, the pyramidal neurons are loosely packed as revealed by the Nissl counterstain. The asterisks indicate where the CA1 pyramidal cell layer divides into two heterotopic principal layers. Note that somatostatin cells (indicated by the solid arrows) are found in the region between the two principal cell layers as well as in the stratum radiatum proper. The hilus and CA3 distribution of SOM interneurons remained normal in Lis $1+/-$ murine brains. Scale bars: $A 1,325 \mu \mathrm{m} ; A 2,125 \mu \mathrm{m} ; B 1,365 \mu \mathrm{m} ; B 2,135 \mu \mathrm{m} ; C 1,315 \mu \mathrm{m} ; C 2,125 \mu \mathrm{m} ; D 1,300 \mu \mathrm{m} ; D 2,100 \mu \mathrm{m}$.

Lis 1 +/ - mice, the distribution of PV-immunoreactive interneurons paralleled the disruption of stratum pyramidale, although the cells themselves were anatomically similar to wild type. It is worthwhile noting that although the somata of PV cells were typically associated with heterotopic pyramidal neurons (Fig. $5 B 1, B 2)$, they were also often observed within stratum radiatum.

Somatostatin-positive interneurons (SOM) account for $\sim 15 \%$ of GABAergic cells in the murine hippocampus (Freund and Buzsaki, 1996). In the CA1 subfield they are normally confined to the stratum oriens-alveus (Fig. 5C1,C2) and are activated in a feedback manner by the axons of CA1 pyramidal neurons (Maccaferri and McBain, 1995). The distribution of SOMimmunoreactive interneurons in Lis $1+/-$ mice resembled that of
Figure 5. Heterotopic somatostatin- and parvalbumin-containing interneurons in the Lis1+/- hippocampus. Immunohistochemical techniques were used to determine the expression pattern of markers specific for inhibitory interneuron populations. $A 1, A 2$, In wild-type hippocampus, parvalbumin $(P V)$ is found in interneurons whose somata are located primarily in the stratum pyramidale and stratum oriens. $A 2$ illustrates a higher magnification of the boxed region in A1. The somatodendritic profile of these cells is generally perpendicular to the principal cell layer. The axons of PV interneurons are largely confined to stratum pyramidale and form a dense plexus around the somata of pyramidal cells. B1, B2, The distribution of PV-containing interneurons in Lis 1+/ - sections closely resembled those found in wild type. Somas maintained their associations with the stratum oriens and stratum pyramidale layers, whereas their axonal processes remained in stratum pyramidale. Consequently, PV-containing interneurons appeared in multiple bands caused by the disorganization of the Lis1+/- stratum pyramidale. $B 2$ illustrates the boxed region in $B 1$ at a higher magnification. Note that PV-positive cell bodies are found in both heterotopic principal cell layers. All immunostained sections have been Nisslcounterstained to allow visualization of the inhibitory interneurons relative to the heterotopic principal cell layers. C1, C2, In wild-type hippocampus, somatostatin $(S O M)$-containing interneurons were predominantly found in CA1 stratum oriensalveus. The CA3 subfield contains a broader distribution of SOM interneurons with somas found in stratum pyramidale, stratum lucidum, and stratum radiatum. The hilar region of the dentate gyrus also contained numerous SOM-positive interneurons. $C 2$, Higher magnification of the boxed region indicated that $C 1$ shows typical somatostatin-containing cells of the CA1 stratum oriens. These cells typically possess horizontally oriented somata and dendrites. $D 1, D 2$, In the CA1 subfield of the Lis1+/hippocampus $(5 \times, 25 \times)$, numerous SOMcontaining interneurons were observed not only in the stratum oriens but were dispersed throughout the clusters of CA1 pyrgion between the two principal cell layers as
rmal in Lis $1+/-$ murine brains. Scale bars:

$$
\text { . }
$$

wild type with one notable exception; SOM-positive interneurons were frequently observed in CA1 stratum radiatum of Lis $1+/-$ hippocampus, subjacent to the innermost pyramidal neurons or between the blades of the heterotopic pyramidal cell layers (Fig. $5 D 1, D 2)$. Such cells were never observed in wild-type hippocampus. In contrast, the distribution of $\mathrm{CB}$ and calretinin-containing interneurons was normal in Lis1+/- mice (data not shown).

\section{Synaptic connectivity, physiology, and plasticity}

Given the abnormal cellular organization of the hippocampus, we next considered whether synaptic connections were correctly established. Using in vitro hippocampal slices, we performed a laminar analysis of field EPSPs (fEPSPs). A stimulating electrode 
A. Wild type $+/+$

Figure 6. Disruption of Schaffer collateral synaptic transmission in the CA1 hippocampus. $A$, Laminar analysis of Schaffer collateral evoked fEPSPs reveals multiple current sinks in the Lis1+/- hippocampus. A stimulating electrode was placed at a fixed position within the stratum radiatum of both wild-type and Lis 1+/- hippocampi. The recording electrode was positioned sequentially in stratum radiatum, stratum pyramidale, and the alveus. In wild-type hippocampus, stimulation of the Schaffer collateral/commissural inputs evoked a negative-going fEPSP in the stratum radiatum (3), which is generated as an active current sink of the apical dendrites of the CA1 pyramids. As the recording electrode was moved into stratum pyramidale (2), a single negative-going population spike superimposed on a positive-going fEPSP was observed. In the alveus (1), a positive-going fEPSP was observed, which represents the source currents of the active pyramids. In contrast, laminar field analysis of the Lis $1+/$ - hippocampus revealed multiple active current sinks throughout all layers of the CA1 subfield. Despite the presence of two distinct pyramidal cell layers, fEPSPs were always negative going, reflecting that synaptic inputs occur over a broadened pyramidal dendritic field. Scale bars: left panel, $43 \mu \mathrm{m}$; right panel, $55 \mu \mathrm{m}$. B. Averaged inputoutput curves of Schaffer collateral/commissural evoked fEPSP (measured as the slope of the initial fEPSP) and fPS amplitude were generated for both wild-type $(n=9)$ and Lis $1+/-(n=10)$ slices. Data were normalized to both the maximal evoked fEPSP (or fPS) and the stimulus intensity range in each experiment to permit comparison between the two groups. In the Lis $1+/-$ hippocampus, both the fEPSP and fPS input-output curves were shifted to the left of the control wild-type hippocampus, indicating an increased excitability and lower threshold for synaptic transmission in the knockout. $C$, Schaffer collater$\mathrm{al} /$ commissural evoked fEPSPs (recorded in stratum radiatum) revealed that the degree of paired-pulse facilitation at all stimulus intervals was similar between wild-type $(n=6)$ and Lis $1+/-$ hippocampus $(n=10)$.


was placed at a fixed position within the stratum radiatum of CA1, and an extracellular electrode was moved sequentially from stratum oriens to stratum lacunosum-moleculare of CA1. In the control hippocampus, stimulation of the Schaffer collateral/commissural fibers evoked positive-going EPSPs in stratum oriens (Fig. 6A). A negative inflection was superimposed on the EPSP when the recording electrode was positioned within stratum pyramidale, which corresponds to the synchronous firing of the pyramidal cell population. A negative potential was generated in stratum radiatum corresponding to the current sink of the apical dendrites of active CA1 pyramidal neurons. As expected from the disruption of the pyramidal cell layer into multiple layers, the laminar profile of Lis $1+/-$ hippocampus was severely disrupted. In all slices tested, synchronous population spikes were observed throughout all regions of the CA1 subfield. The population spike was typically combined with a negative potential representing the fEPSP, which could be recorded in isolation further toward the inferior stratum radiatum where few pyramidal cell bodies were observed. This field potential reversed polarity only when mea- surements were made at the stratum oriens-alveus border (Fig. $6 A$, top trace). This indicates that both inferior and superior pyramidal cells are functionally innervated and capable of contributing to information flow through the hippocampal circuit.

To determine whether synaptic transmission was abnormal in the Lis $1+/-$ hippocampus, we analyzed the input-output (I-O) curves of both the Schaffer collateral evoked fEPSP and the field population spike (fPS) (Fig. 6B). I-O curves were normalized to the maximal stimulus intensity and the maximal field response to allow a comparison between slices, and between wild type versus Lis $1+/-$. Both the fEPSP and the fPS I-O curves in Lis $1+/-(n=$ 10) were shifted to the left compared with wild-type controls $(n=$ 9). At a stimulus intensity that activated $50 \%$ of the maximal fPS and fEPSP in wild type, the same stimulus evoked $68 \pm 4 \%$ and $62 \pm 3 \%$ in Lis $1+/-$, respectively, demonstrating an enhanced excitability in the Lis $1+/-$ CA1 pyramidal cell layer $(p=0.01$, Student's $t$ test). The maximal fEPSP and fPS evoked in Lis $1+/-$ CA1 pyramidal cell layer was not significantly different from wild type; mean maximal fEPSP $=1.65 \pm 0.28 \mathrm{mV}(n=10)$ compared 
with $1.50 \pm 0.32 \mathrm{mV}(n=9)$ in control, mean maximal $\mathrm{fPS}=6.34$ $\pm 0.89 \mathrm{mV}(n=10)$ compared with $5.64 \pm 0.86 \mathrm{mV}(n=9)$ in control. In contrast, fEPSP I-O curves from associational/commissural inputs $(n=7)$ or mossy fibers $(n=7)$ onto Lis $1+/-$ CA3 pyramidal neurons were not different from wild type $(n=6)$ (data not shown).

We next examined short- and long-term mechanisms of plasticity of excitatory synapses onto both CA1 and CA3 pyramidal neurons.

\section{Schaffer collateral-CA1 synapses}

Paired-pulse facilitation was not different between Lis1+/- and wild-type hippocampus (Fig. $6 C$ ). Potentiation of the fEPSP slope peaked at an interval of $\sim 50 \mathrm{msec}$ with a maximal enhancement of $52.9 \pm 5.8$ and $45.9 \pm 13.5 \%(n=6)$ in Lis $1+/-$ and wild-type hippocampus, respectively. Similarly, post-tetanic potentiation and long-term potentiation (LTP) (three trains of $100 \mathrm{~Hz} \times 1 \mathrm{sec}$ duration) at Schaffer collateral-CA1 synapses were normal in Lis 1 + / - hippocampus. LTP was stable for at least $30 \mathrm{~min}$ after induction and averaged $133.7 \pm 4.1 \%(n=10)$ for Lis $1+/-$ versus $135.4 \pm 6.3 \%(n=6)$ for wild type (data not shown).

Using whole-cell current- and voltage-clamp recordings, CA1 pyramidal neurons had resting membrane potentials of $-50.4 \pm$ $1.5 \mathrm{mV}$ and input resistances of $140 \pm 13 \mathrm{M} \Omega$, values similar to those of wild-type neurons. Threshold for action potential generation was $-39.3 \pm 2.4 \mathrm{mV}$, and action potentials were themselves not unusual, with $10-90 \%$ rise time of $0.8 \pm 0.1 \mathrm{msec}$ and half-widths of $2.1 \pm 0.28 \mathrm{msec}(n=8)$.

\section{Mossy fiber-CA3 synapses}

We next determined whether the granule cell hypertrophy in the Lis 1+/- mouse altered transmission at mossy fiber synapses. Using extracellular field recordings, we studied frequencydependent facilitation at mossy fiber synapses, which in striking contrast to associational/commissural synapses onto CA3 pyramidal neurons exhibit temporal integration even at very low stimulation frequencies (Salin et al., 1996). Figure $4 B, C$ shows experiments in which the stimulus frequency was increased in a series of steps from 0.025 to $0.33 \mathrm{~Hz}$. At wild-type mossy fiber synapses, facilitation occurred at frequencies as low as $0.05 \mathrm{~Hz}$ and reached a magnitude of more than sixfold $(642.1 \pm 92.1 \%$, $n=8$ ) at $0.33 \mathrm{~Hz}$, similar to previous reports (Salin et al., 1996). Consistent with previous reports, the magnitude of facilitation was markedly reduced by the induction of LTP $(4 \times 100 \mathrm{~Hz}, 0.03$ $\mathrm{Hz}$, in the presence of $50 \mu \mathrm{M}$ DL-APV), which acts to increase the probability of transmitter release. At $0.33 \mathrm{~Hz}$ the maximal facilitation was now $48 \%$ of control $(312 \pm 34.6 \%, n=8)$. Identical experiments in Lis $1+/-$ revealed that mossy fiber-CA3 synapses possessed a significantly smaller degree of facilitation at all frequencies tested compared with wild type: the maximal facilitation at $0.33 \mathrm{~Hz}$ was $400.3 \pm 43.0(n=8, p<0.001$, two tailed Student's $t$ test). After LTP induction, the dynamic range of frequency facilitation was reduced further; the maximal facilitation measured at $0.33 \mathrm{~Hz}$ was $59 \%(237 \pm 23.5 \%, n=8)$ of that seen during the control period. Of interest, the degree of maximal facilitation (measured at $0.33 \mathrm{~Hz}$ ) observed in both wild type and Lis 1 +/ - after induction of LTP was not significantly different (312 \pm 34.6 in control versus $237 \pm 23.5$ in Lis $1+/-, p=0.1)$. The magnitude of LTP (30 min after induction) observed at both wild-type and Lis1+/- mossy fiber synapses was not significantly different $(298 \pm 51 \%$ in wild type, $n=8$ vs $276 \pm 32 \%$ in Lis $1+/-, n=8$,). Taken together these data demonstrate that mossy fiber synapses in the Lis $1+/-$ are less excitable than wild type. Moreover, under control conditions the dynamic range of facilitation in the Lis $1+/-$ is less than wild type, attributable in part to a difference in the initial release probability of the Lis $1+/-$ mossy fiber synapses.

\section{The Lis1+/- hippocampus is predisposed to electrographic activity in the elevated $\left[\mathrm{K}^{+}\right]_{\mathrm{o}}$ model of epilepsy.}

Seizures are practically universal in humans with Type I lissencephaly (Dobyns et al., 1993). Lethal tonic-clonic seizures were observed in several Lis1 mutant mice (of all ages) but to date have not been studied in any detail (Hirotsune et al., 1998); however, spontaneous epileptiform activity was not observed in the extracellular field potential recorded from the in vitro hippocampus. Because neurotransmission at both mossy fiber and Schaffer collateral synapses was altered, we wanted to determine whether the Lis $1+/$ - hippocampus was susceptible to electrographic seizure activity.

Extracellular field potentials were recorded from hippocampal CA1 stratum pyramidale exposed to modest elevations of $\left[\mathrm{K}^{+}\right]_{\mathrm{o}}$, the so-called High $\mathrm{K}^{+}$model of epilepsy, a model for status epilepticus (McBain et al., 1993). In general, both wild-type and Lis 1+/- slices did not display spontaneous interictal bursts until $\left[\mathrm{K}^{+}\right]_{\mathrm{o}}$ was elevated to $6.5 \mathrm{~mm}$ (Fig. 7). Intense, spontaneous interictal bursts were observed in all Lis $1+/-$ slices on exposure to $6.5 \mathrm{~mm}\left[\mathrm{~K}^{+}\right]_{\mathrm{o}}(n=14)$ (Fig. $\left.7 A, B\right)$. In contrast, only $\sim 75 \%$ of wild-type slices reached bursting threshold in $6.5 \mathrm{~mm}\left[\mathrm{~K}^{+}\right]_{\mathrm{o}}(n=$ 13); however, these bursts were usually composed of only three to five spike trains, in contrast to the hypersynchronous events recorded under similar conditions in the Lis1+/- slices. These data are consistent with the enhanced excitability of Schaffer collateral-CA1 synapses observed in the input-output experiments.

To compare interictal burst intensity in different $\left[\mathrm{K}^{+}\right]_{\mathrm{o}}$, we used the method of coastline bursting index (Korn et al., 1987) to quantify the electrographic waveform. CBI is sensitive to changes in the number or amplitude of population spikes, and it increases when neuronal synchrony, firing frequency or duration, or the number of participating neurons increases. In wild-type slices $(n=13)$, interictal bursts were most intense in $8.5 \mathrm{~mm}\left[\mathrm{~K}^{+}\right]_{\mathrm{o}}$. The relative CBIs were $286 \pm 103,544 \pm 178$, and $263 \pm 177$ in 6.5 , 8.5 , and $10.5 \mathrm{~mm}\left[\mathrm{~K}^{+}\right]_{\mathrm{o}}$, respectively (Fig. $7 B$ ). In contrast, interictal bursting in the Lis $1+/-$ hippocampus $(n=14)$ was most intense at $6.5 \mathrm{~mm}\left[\mathrm{~K}^{+}\right]_{\mathrm{o}}$ and had a CBI approximately fourfold greater than wild type (mean $863+80, p<0.0001$, Student's unpaired $t$ test). In Lis $1+/-$ slices, burst intensity waned on exposure to 8.5 and $10.5 \mathrm{~mm}\left[\mathrm{~K}^{+}\right]_{\mathrm{o}}$ (mean $\mathrm{CBI}=319 \pm 120$ and $88 \pm 36$, respectively). It is worthwhile mentioning that the maximal interictal burst intensity in wild-type slices was always significantly less than the maximal burst intensity observed in Lis $1+/-$ slices at $6.5 \mathrm{~mm}\left[\mathrm{~K}^{+}\right]_{\mathrm{o}}$.

In $6.5 \mathrm{mM}\left[\mathrm{K}^{+}\right]_{\mathrm{o}}$, interictal burst frequency was similar in both wild-type and $\mathrm{Lis} 1+/-$ slices $(0.15 \pm 0.03, n=13$ and $0.16 \pm 0.03$ $\mathrm{Hz}, n=14$, respectively). In contrast, in $8.5 \mathrm{~mm}\left[\mathrm{~K}^{+}\right]_{\mathrm{o}}$, burst frequency more than doubled in the Lis $1+/-$ slices $(0.35 \pm 0.05$ $\mathrm{Hz}$ ), whereas the frequency of bursts in wild type remained unchanged $(0.18 \pm 0.07 \mathrm{~Hz})$. In experiments in which we recorded simultaneously from two heterotopic bands of CA1 pyramidal neurons, interictal bursts were synchronous in the extracellular recording from both cell layers, suggesting that despite belonging to distinct cell layers both sets of cells are paced by an identical mechanism (data not shown). 


\section{A. Wild type}
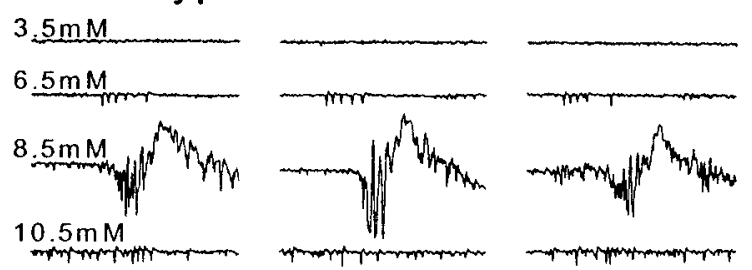

Lis $1+/-$
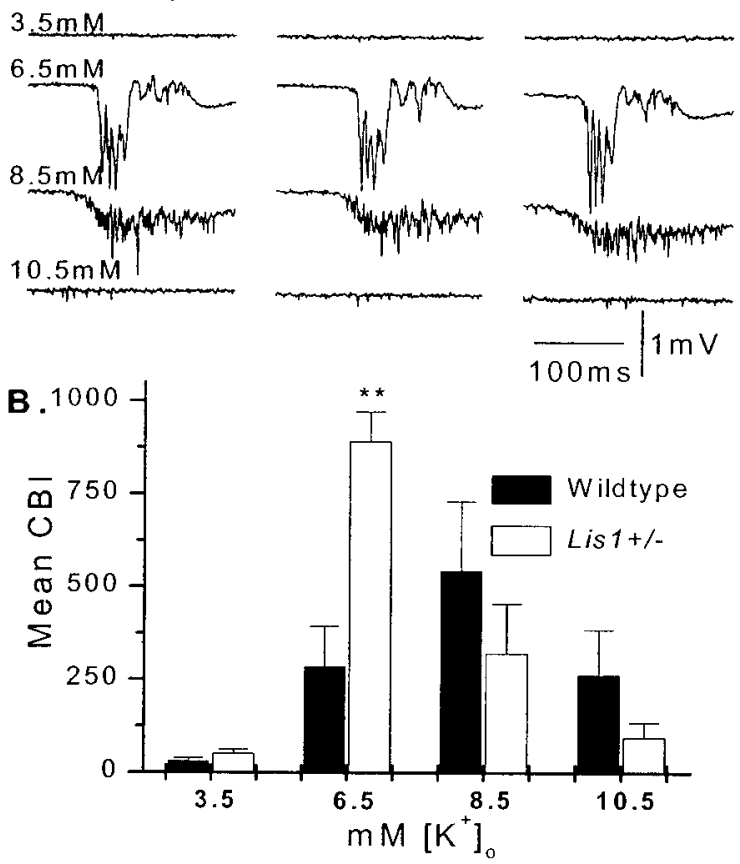

Figure 7. The Lis1+/- hippocampus is predisposed to interictal burst firing. Extracellular recording electrodes were positioned within the stratum pyramidale to monitor the threshold and intensity of spontaneous interictal bursts in response to elevation of $\left[\mathrm{K}^{+}\right]_{\mathrm{o}} . A$ shows two representative experiments from wild-type and $L i s 1+/-$ hippocampal slices. In wild-type hippocampus, interictal bursts were initiated in $75 \%$ of slices exposed to $6.5 \mathrm{~mm}\left[\mathrm{~K}^{+}\right]_{\mathrm{o}}(n=13)(A, B)$. Bursts in $6.5 \mathrm{~mm}\left[\mathrm{~K}^{+}\right]_{\mathrm{o}}$ were generally small and consisted of small clusters of spikes of low intensity. In wild type, the most intense, robust bursts were observed in $8.5 \mathrm{~mm}$ $\left[\mathrm{K}^{+}\right]_{\mathrm{o}}$. At $10.5 \mathrm{~mm}\left[\mathrm{~K}^{+}\right]_{\mathrm{o}}$, spontaneous interictal activity decreased in intensity, and clusters of spikes became disorganized $(A, B)$. In contrast, interictal burst firing was observed in all Lis $1+/-$ exposed to $6.5 \mathrm{~mm}$ $\left[\mathrm{K}^{+}\right]_{\mathrm{o}}$, and was most intense compared with all other $\left[\mathrm{K}^{+}\right]_{\mathrm{o}}(A, B)$. Burst intensity decreased on further elevation of $L i s 1+/-$ slices to 8.5 and 10.5 $\mathrm{mm}\left[\mathrm{K}^{+}\right]_{\mathrm{o}} B$, Histograms to show the mean coastline bursting index (Mean CBI) for both wild-type and Lis1+/- interictal bursting in all $\left[\mathrm{K}^{+}\right]_{\mathrm{o}}$ conditions. Interictal bursting in Lis $1+/-$ slices was significantly more intense at $6.5 \mathrm{~mm}\left[\mathrm{~K}^{+}\right]_{\mathrm{o}}$ than wild type $(p<0.0001)$.

\section{DISCUSSION}

ILS and MDS result from haplo-insufficiency at chromosome $17 \mathrm{p} 13.3$, and recent evidence has determined that mutation or deletion of the LIS1 gene within band 17p13.3 is responsible for lissencephaly. The conservation of linkage between the human $17 \mathrm{p} 13.3$ and the mouse 11B2 gene has permitted the generation of an animal model for the study of human lissencephaly (Hirotsune et al., 1998; Walsh 1998, 1999). Although incomplete development of the hippocampal formation has been reported in Type I lissencephaly (Pilz and Quarrell 1996), the anatomical malformations of the hippocampus associated with ILS or MDS have not been previously described in detail. In the present study, the Lis 1+/- mouse hippocampus displayed malformation and neu- ronal heterotopia across all principal cell layers. Dysplasia and generalized neuronal heterotopias are common features of ILS brains and are presumed to contribute to the severe mental retardation and seizure disorders commonly associated with classical lissencephaly. In addition, we show that hippocampal malformations within the Lis 1+/- mutant are associated with perturbations in excitatory synaptic transmission and a lowered threshold for intense interictal burst firing.

A number of cortical abnormalities have been associated with human epileptogenesis. These include (but are not restricted to) abnormal dendritic branching (Belichenko et al., 1994), altered synaptic transmission (Avoli and Williamson, 1996), loss or compromise of inhibitory interneuron function (Ferrer et al., 1992), and perturbed receptor subunit expression (Ying et al., 1998a,b). Several of these abnormalities may be responsible for the enhanced excitability observed in the Lis $1+/-$ hippocampus.

Golgi analysis of pyramidal cell dendritic arbor revealed that heterotopic CA1 pyramidal neurons possessed less elaborate basal dendritic trees with fewer branch points than wild type. These findings provide an epigenetic link between migration and development, because the amount of branching was correlated with the extent of the heterotopia. In addition, abnormalities of dendritic morphology are common in cortical neurons of human partial epilepsy (Belichenko et al., 1994), and neuronal modeling studies have demonstrated that alteration of dendritic morphology can significantly affect neuronal firing patterns (Mainen and Sejnowski 1996). Furthermore, mossy fiber sprouting and reorganization in the dentate gyrus are common features of many models of temporal lobe epilepsy. Neuroplastic changes of granule cell dendrites, although less characterized, have been described after tetanic stimulation of the perforant path projection, a model of temporal lobe epilepsy (Spigelman et al., 1998). The presence of basilar dendrites extending into the subgranular region suggests that these heterotopic granule cells may be postsynaptic targets for mossy fiber axons. Interestingly, mossy fiber transmission was not hyperexcitable as seen in the CA1 subfield, but possessed a lower dynamic range of frequency facilitation. Because inhibitory interneurons of the CA3 subfield are the primary targets of mossy fiber synaptic transmission (Acsády et al., 1998), it is possible that the narrow range of facilitation of mossy fiber transmission impacts the degree of recruitment of feedforward inhibition to the CA3 subfield, consequently resulting in an enhancement of hippocampal excitability.

Although Schaffer collateral excitatory synaptic inputs onto heterotopic CA1 pyramidal neurons were functional, analysis of the input-output properties of the fPS and fEPSP revealed enhanced excitability of the Lis1 +/- CA1 subfield without a change in the maximal fEPSP or fPS amplitude. Whether this reflects an alteration in the inhibitory-excitatory "balance" within the hippocampus attributable to alterations in inhibitory interneuron innervation or alternatively to an alteration of receptor subunit expression remains to be determined. Whole-cell patch-clamp recordings from individual $L i s 1+/-$ CA1 pyramidal neurons revealed no change in neuronal resting membrane potential, input resistance, or threshold for action potential generation. This enhancement of synaptic transmission presumably contributes to the lowered threshold and intense epileptogenesis observed in the Lis $1+/-$ mouse. How does an absence of LIS1 protein alter synaptic function? In addition to its role in neuronal migration, PAF also regulates synaptic transmission and has been identified as a retrograde transmitter in various forms of LTP (Kato et al., 1994; Kato and Zorumski 1996). Increased concentrations of 
PAF have also been shown to result in massive glutamate exocytosis (Bazan and Allan, 1996), reducing the readily releasable pool of transmitter, which may account for the lower degree of synaptic facilitation observed at mossy fiber synapses. Taken together, it is possible that the alterations of synaptic transmission seen in the present experiments are a secondary consequence of the reduction of LIS1 protein, Pafah1b1, which presumably will impact PAF metabolism. The role of PAF regulation of synaptic activity is presumably independent from its role in development and migration.

Numerous animal models of epilepsy have been generated by compromise of various aspects of GABAergic inhibitory neurotransmission. Although we did not detect a loss of any specific inhibitory interneuron population, both somatostatin- and parvalbumin-containing interneurons were ectopically placed in the CA1 stratum radiatum. Both interneuron types represent distinct populations of GABAergic cells involved in the regulation of neuronal excitability and the generation of intrinsic oscillations (Freund and Buzsaki, 1996). The axons of PV interneurons were observed to form "baskets" around heterotopic pyramidal cell somata, suggesting that these cells correctly innervated their targets despite marked heterotopia of the principal cell layer. Neurogenesis of nonpyramidal, GABAergic interneurons that lie within the pyramidal layer (presumably parvalbuminpositive cells) occurs within the hippocampal plate and simultaneously with principal neurons (Seress and Ribak 1988; Soriano et al., 1989) and may explain the "accuracy" of the axon targeting. The axons of SOM interneurons usually project to the CA1 stratum lacunosum-moleculare (McBain et al., 1994) to regulate the temporoammonic input from the entorhinal cortex (Maccaferri and McBain, 1995). Whether SOM interneurons in the Lis 1+/- hippocampus correctly innervate their targets and regulate the temporoammonic input is a subject for future study. Although both calbindin and calretinin interneurons were present and appeared to be positioned within the appropriate layers of the hippocampus, their characteristic diff use position within the hippocampus did not permit an accurate assessment of whether these cells are positioned correctly. Future analysis of all inhibitory interneurons' axon targets will be required to determine whether inhibitory interneurons correctly innervate their targets.

A causal link between cortical and hippocampal malformations and epilepsy is well established (Chavassus-au-Louis et al., 1999). The recently renewed interest in "neuronal migration disorders" has arisen from the availability of a number of animal models (Chavassus-au-Louis et al., 1999; Walsh 1999). Such models currently include spontaneous murine mutants (e.g., telencephalic internal structural heterotopia, reeler), gestational teratogenic exposure, exposure to the DNA alkylating agent, methylazoxymethanol, or x-irradiation. Unlike these models, in this study we have investigated a mouse model of a human genetic neuronal migration disorder. How good a model for ILS is the Lis1+/animal? The Lis $1+/-$ mice display migration defects in the hippocampus, cortex, and cerebellum (Hirotsune et al., 1998), all areas affected in ILS patients. In addition, behavioral testing has demonstrated motor and cognitive impairments in Lis 1+/- mice (R. Paylor, S. Hirotsune, M. Gambello, J. Crawley, and A. Wynshaw-Boris, unpublished observations) that are consistent with ILS. Although Lis1+/- hippocampal slices did not show spontaneous electrographic activity in vitro, the present study has highlighted numerous anatomical defects consistent with a predisposition to electrographic activity. Moreover, in a model for status epilepticus, a severe form of epilepsy common in lissen- cephaly, we demonstrate that $L i s 1+/-$ mice have a reduced threshold for interictal activity and more intense interictal bursts than seen at any $\left[\mathrm{K}^{+}\right]_{\mathrm{o}}$ in wild-type mice (Fig. $7 C$ ). Future experiments are targeted toward determining the precise mechanisms leading to epileptiform activity and how antiepileptic drugs impact the epileptiform activity recorded in the Lis 1+/hippocampus. Finally, simultaneous recordings from distally located bands of heterotopic CA1 pyramidal neurons in slices exposed to elevated $\left[\mathrm{K}^{+}\right]_{\mathrm{o}}$ revealed that epileptiform activity occurred synchronously. This suggests that heterotopic regions are functionally linked to the hippocampal network and support synchronous hyperexcitability presumably driven by common afferents from the CA3 subfield. Taken together these data would suggest that the Lis $1+/-$ animal provides an extremely powerful model for Type 1 lissencephaly.

In conclusion, we provide a new model for Type 1 lissencephaly-related epilepsy. A 50\% reduction in LIS1 protein disrupts the normal migration of pyramidal neurons, dentate granule cells, and interneurons in the hippocampus. This migrational defect is associated with both anatomical disorganization and morphological abnormalities, including sparse dendritic branching in pyramidal cells and granule cell hypertrophy. Despite this disorganization, some pathways appear to find their appropriate targets, whereas others do not. The cumulative result of these abnormalities is a hyperexcitable hippocampus. At the moment, we cannot rule out the possibility that cortical migrational defects also contribute to the human seizure phenotype. This will be tested in the future using the conditional Lis1 mutant (Hirotsune et al., 1998) mated to transgenic mice that express Cre exclusively either in the developing cortex or hippocampus. The present data, however, would suggest that more attention should be paid to the hippocampal formation in the various human neuronal migration disorders (Walsh et al., 1998) as a possible focus for seizure related activity. How a reduction of Lis1 protein results in such disruption of hippocampal anatomy and function is at present unclear, but the present experiments provide a detailed description of the hippocampal Lis $1+/-$ phenotype in which to study more closely the nature of the LIS1 protein.

\section{REFERENCES}

Acsády L, Kamondi A, Sík A, Freund TF, Buzsáki G (1998) GABAergic cells are the major postsynaptic targets of mossy fibers in the rat hippocampus. J Neurosci 18:3386-3403.

Albrecht U, Abu-Issa R, Ratz B, Hattori M, Aoki J, Arai H, Inoue K, Eichele G (1996) Platelet-activating factor acetylhydrolase expression and activity suggest a link between neuronal migration and plateletactivating factor. Dev Biol 180:579-593.

Avoli M, Williamson A (1996) Functional and pharmacological properties of human neocortical neurons maintained in vitro. Prog Neurobiol 48:519-554.

Barkovich AJ, Koch TK, Carrol CL (1991) The spectrum of lissencephaly: report of ten patients analyzed by magnetic resonance imaging. Ann Neurol 30:139-146.

Bazan NG, Allan G (1996) Platelet-activating factor in the modulation of excitatory amino acid neurotransmitter release and of gene expression. J Lipid Mediat Cell Signal 14:321-330.

Belichenko P, Sourander P, Dahlstrom A (1994) Morphological aberrations in therapy-resistant partial epilepsy (TRPE). Mol Neurobiol 9:245-252.

Bix GJ, Clark GD (1998) Platelet-activating factor receptor stimulation disrupts neuronal migration in vitro. J Neurosci 18:307-318.

Chavassus-au-Louis N, Baraban SC, Gaiarsa J-L, Ben-Ari Y (1999) Cortical malformations and epilepsy: new insights from animal models. Epilepsia 40:811-821.

Clark GD, McNeil RS, Bix GJ, Swann JW (1995) Platelet-activating factor produces neuronal growth cone collapse. NeuroReport 6:2569-2575. 
Cowan WM, Stanfield BB, Kishi K (1980) The development of the dentate gyrus. Curr Topics Dev Biol 15:103-157.

Dobyns WB, Truwit CL (1995) Lissencephaly and other malformations of cortical development: 1995 update. Neuropediatrics 26:132-147.

Dobyns WB, Reiner O, Carrozzo R, Ledbetter DH (1993) Lissencephaly, a human brain malformation associated with deletion of the LIS1 gene located at chromosome 17p13. JAMA 270:2838-2842.

Ferrer I, Pineda M, Tallada M, Oliver B, Russi A, Oller L, Noboa R, Zujar MJ, Alcantara S (1992) Abnormal local-circuit neurons in epilepsia partialis continua associated with focal cortical dysplasia. Acta Neuropathol 83:647-652.

Franck JE, Pokorny J, Kunkel DD, Schwartzkroin PA (1995) Physiologic and morphologic characteristics of granule cell circuitry in human epileptic hippocampus. Epilepsia 36:543-558.

Freund TF, Buzsaki G (1996) Interneurons of the hippocampus. Hippocampus 6:347-470.

Hattori M, Adachi H, Tsujimoto M, Arai H, Inoue K (1994) MillerDieker lissencephaly gene encodes a subunit of brain platelet-activating factor acetylhydrolase. Nature 370:216-218.

Hirotsune S, Fleck MW, Gambello MJ, Bix GJ, Chen A, Clark GD, Ledbetter DH, McBain CJ, Wynshaw-Boris A (1998) Graded reduction of Pafah1b1 (Lis1) activity results in neuronal migration defects and early embryonic lethality. Nat Genet 19:333-339.

Kato K, Zorumski CF (1996) Platelet activating factor as a potential retrograde messenger. J Lipid Mediat Cell Signal 14:341-348.

Kato K, Clark DG, Bazan NG, Zorumski CF (1994) Platelet activating factor as a potential retrograde messenger in CA1 hippocampal longterm potentiation. Nature 367:1211-1216.

Korn SJ, Giachino JL, Chamberlin NL, Dingledine R (1987) Epileptiform burst activity induced by potassium in the hippocampus and its regulation by GABA-mediated inhibition. J Neurophysiol 57:325-340.

Lo Nigro C, Chong SS, Smith ACM, Dobyns WB, Carrozzo R, Ledbetter DH (1997) Point mutations and an intragenic deletion in LIS1, the lissencephaly causative gene in isolated lissencephaly sequence and Miller-Dieker syndrome. Hum Mol Genet 6:157-164.

Maccaferri G, McBain CJ (1995) Passive propagation of LTD to stratum oriens-alveus inhibitory neurons modulates the temporoammonic input to the hippocampal CA1 region. Neuron 15:137-145.

Mainen Z, Sejnowski TJ (1996) Influence of dendritic structure on firing pattern in model neocortical neurons. Nature 382:363-366.

McBain CJ, Traynelis SF, Dingledine R (1993) High potassium induced synchronous bursts and electrographic seizures. In: Models and concepts in epilepsy research (Schwartzkroin PA, ed), pp 437-461. Cambridge, UK: Cambridge UP.

McBain CJ, DiChiara T, Kauer JA (1994) Activation of metabotropic glutamate receptors differentially affects two classes of hippocampal interneurons and potentiates excitatory synaptic transmission. J Neurosci 14:4433-4445.

Morris NR, Efimov VP, Xiang X (1998a) Nuclear migration nucleokinesis and lissencephaly. Trends Cell Biol 8:476-470.
Morris NR, Albrecht U, Reiner O, Eichele G, Yu-Lee LY (1998b) The lissencephaly gene product Lis1, a protein involved in neuronal migration, interacts with a nuclear movement protein NudC. Curr Biol 8:603-606.

Pilz DT, Quarrell OWJ (1996) Syndromes with lissencephaly. J Med Genet 33:319-323.

Reiner O, Carrozzo R, Shen Y, Wehnert M, Faustinella F, Dobyns WB, Caskey CT, Ledbetter DH (1993) Isolation of a Miller-Dieker lissencephaly gene containing $\mathrm{G}$ protein b-subunit-like repeats. Nature 364 717-721.

Reiner O, Albrecht U, Gordon M, Chianese KA, Wong C, Gal-Gerber O, Sapir T, Siracusa LD, Buchberg AM, Caskey CT (1995) Lissencephaly gene (LIS1) expression in the CNS suggests a role in neuronal migration. J Neurosci 15:3730-3738.

Salin PA, Scanziani M, Malenka RC, Nicoll RA (1996) Distinct short term plasticity at two excitatory synapses in the hippocampus. Proc Natl Acad Sci USA 93:13304-13309.

Sapir T, Elbaum M, Reiner O (1997) Reduction of microtubule catastrophe events by LIS1, platelet activating factor acetylhydrolase subunit. EMBO J 16:6877-6984.

Seress L, Mrzljak L (1987) Basal dendrites of granule cells are normal features of fetal and adult dentate gyrus of both monkey and human hippocampal formations. Brain Res 405:169-174.

Seress L, Ribak CE (1988) The development of GABAergic neurons in rat hippocampal formation. An immunocytochemical study. Dev Brain Res 44:197-209.

Soriano E, Cobas A, Fairen A (1989) Neurogenesis of glutamic acid decarboxylase immunoreactive cells in the hippocampus of the mouse. I: Regio superior and regio inferior. J Comp Neurol 281:603-611.

Soriano E, Del Rio JA, Martinez A, Super H (1994) Organization of the embryonic and early postnatal murine hippocampus. I. Immunocytochemical characterization of neuronal populations in the subplate and marginal zone. J Comp Neurol 342:571-595.

Spigelman I, Yan XX, Obenaus A, Lee EYS, Wasterlain CG, Ribak CE (1998) Dentate granule cells form novel basal dendrites in a rat model of temporal lobe epilepsy. Neuroscience 86:109-120.

Valverde F (1976) Aspects of cortical organization related to the geometry of neurons with intra-cortical axons. J Neurocytol 5:509-529.

Walsh CA (1998) LISsen up! Nat Genet 19 307-308.

Walsh CA (1999) Genetic malformations of the human cerebral cortex. Neuron 23:19-29.

Ying Z, Babb TL, Comair YG, Bushey M, Touhalisky K (1998a) Increased densities of AMPA GluR1 subunit proteins and presynaptic mossy fiber sprouting in the fascia dentata of human hippocampal epilepsy. Brain Res 6:239-246.

Ying Z, Babb TL, Comair YG, Bingaman W, Bushey M, Touhalisky K (1998b) Induced expression of NMDAR2 proteins and differential expression of NMDAR1 splice variants in dysplasic neurons of human epileptic neocortex. J Neuropathol Exp Neurol 57:47-62. 